\title{
Renewable Energy and Economic Growth: Evidence from European Countries
}

\author{
Stamatios Ntanos ${ }^{1}$ (D), Michalis Skordoulis ${ }^{2, *(\mathbb{D})}$, Grigorios Kyriakopoulos ${ }^{3}$ (D), \\ Garyfallos Arabatzis ${ }^{2}$, Miltiadis Chalikias ${ }^{4}$, Spyros Galatsidas ${ }^{2}$, Athanasios Batzios ${ }^{5}$ \\ and Apostolia Katsarou ${ }^{6}$ \\ 1 Department of Business Administration, School of Business, Economics and Social Sciences, \\ University of West Attica, 12244 Egaleo, Greece; sdanos@ath.forthnet.gr \\ 2 Department of Forestry and Management of the Environment and Natural Resources, \\ School of Agricultural and Forestry Sciences, Democritus University of Thrace, 68200 Orestiada, Greece; \\ garamp@fmenr.duth.gr (G.A.); sgalatsi@fmenr.duth.gr (S.G.) \\ 3 School of Electrical and Computer Engineering, National Technical University of Athens, 15780 Zografou, \\ Greece; gregkyr@chemeng.ntua.gr \\ 4 Department of Tourism Management, School of Business, Economics and Social Sciences, \\ University of West Attica, 12244 Egaleo, Greece; mchalikias@hotmail.com \\ 5 Department of Agricultural Economics, School of Agriculture, Faculty of Agriculture, \\ Forestry and Natural Environment, Aristotle University of Thessaloniki, 54124 Thessaloniki, Greece; \\ thanos.batzios@gmail.com \\ 6 Department of Education Sciences in Early Childhood, Democritus University of Thrace, \\ 68100 Alexandroupolis, Greece; aposkats2@psed.duth.gr \\ * Correspondence: mskordoulis@gmail.com
}

Received: 10 July 2018; Accepted: 24 July 2018; Published: 26 July 2018

\begin{abstract}
This paper aims at examining the relationship between energy consumption deriving from renewable energy sources, and countries' economic growth expressed as GDP per capita concerning 25 European countries. The used dataset involves European countries' data for the period from 2007 to 2016. The statistical analysis is based on descriptive statistics, cluster analysis, and autoregressive distributed lag (ARDL), and reveals that all variables are related; this suggests a correlation between the dependent variable of GDP and the independents of renewable energy sources (RES) and Non-RES energy consumption, gross fixed capital formation, and labor force in the long-run. Furthermore, the results show that there is a higher correlation between RES' consumption and the economic growth of countries of higher GDP than with those of lower GDP. The obtained results are consistent with other papers reviewed in this study.
\end{abstract}

Keywords: renewable energy; energy consumption; Gross Domestic Product; economic growth

\section{Introduction}

During the last decades, a continuing shift from conventional to non-conventional sources of energy has been taking place [1,2]. Due to negative environmental effects of conventional energy forms of production and usage, and the finite yields of conventional sources of energy, the need for renewable energy sources (RESs) usage is becoming urgent [3]. Thus, special policies are developed to further promote the expansion of RESs. A critical environmental target of the European Union is to cover $20 \%$ of its energy needs with RESs until 2020. In a global context of analysis, about $19 \%$ of total energy usage is produced from RESs, while the strategic planning is to increase their usage by $50 \%$ by 2050 [4]. 
Relative to the abovementioned shift to RESs, a key question that arises is how their usage is valued under economic constraints, a question that has motivated a plethora of research interest worldwide [4]. Thus, there is ongoing research developed to investigate the relationship between RES and economic growth mainly attributed to the gross domestic product (GDP) [4].

The relevant literature nexus basically contains studies grouped on geographical distribution [2,4-10]. In most of the publications, methodological analysis included statistical models and case controls. Almost all the reviewed publications unveil a relationship that is developed between the level of national economic growth and the quantities of RESs used, especially over the long-run [4-11]. Several publications also investigate the association between economic development and RES-produced energy, to determine those variables that stimulate the others [4-11]. In most of the cases GDP is the dependent variable, while RES consumption, gross fixed capital formation (GFCF), and labor force are the main commonly examined predictors. A positive correlation is also recorded between GDP, RES usage, GFCF, and labor force in most of the cases [4-11]. These results emphasize the significant role of RES to economic growth.

Our research examines the interaction between economic growth and the energy produced by RES. Data concerning 25 European countries for the period between 2007 and 2016 is statistically analyzed; our main results indicate that there are two main groups of countries classified on RES consumption. RES consumption seems to be correlated with the economic growth of the countries examined. However, this correlation is highly bounded on countries with higher GDP.

\section{Literature Review}

\subsection{Non-European Countries}

Salim et al. [12] perform data analysis on OECD countries for the period 1980-2011. Their analysis reveals a long-run relationship that links energy consumption (both green and conventional) with industrial production and economic growth. In addition, evidence of a two-way relationship between conventional energy consumption and GDP growth was found in the short run. According to these results, the expansion of RESs is a viable solution to tackle energy security and climate change, while the gradual replacement of fossil fuels with RESs promotes a sustainable energy economy [12]. Under the same research context, Apergis and Payne [13] use data from 80 countries. They develop a statistical model where GDP is the dependent variable, while the main explanatory variables are electricity consumption from RESs and from conventional sources, among several macroeconomic variables. The results reveal a two-way relationship between RES consumption, conventional energy, and GDP, both in the short and long run. There is also a two-way short-run relationship between renewable and non-renewable forms of energy, which means that it is feasible to swap between energy forms.

In a similar publication, the effect of RESs on economic growth, including biomass, geothermal, wind and solar energyd and hydroelectricity is examined in 38 countries, which are classified into three groups [14]. For the 24 countries of the first group, RESs are significantly correlated to economic growth. Concerning the countries belonging to the second group, energy consumption is negatively associated to economic development. For the other countries of the third group, there is no impact of RES consumption on economic growth.

In the same research field, Inglesi-Lotz [15] analyzes panel data. In this dataset, GDP is the dependent variable, while the following independent variables are namely applied: RES consumption, RES percentage on the examined countries' energy mix, labor force, research and development costs, and capital formation. The results of the statistical analysis show that a $1 \%$ increase in RES consumption can increase the total GDP by $0.105 \%$, while a $1 \%$ increase in the share of RESs in a country's energy mix can increase total GDP by $0.089 \%$.

In the search of RES consumption determinants, Omri and Nguyen [16] use data concerning 64 countries for the years between 1990 and 2011. In all of the countries' clusters, results point out that environmental degradation is a significant variable. Moreover, the price of oil impacts the 
consumption of RESs. Lastly, changes in GDP affect the consumption of RESs only for very high and very low-income countries, while changes in trade openings have a statistically significant effect on the RES consumption in all the examined countries except for those of high income.

In the same scientific field, Al-Mulali et al. [17] conclude that RES consumption plays a key role in promoting economic growth for most of the countries as RESs are a net source of energy, having minimal environmental impacts. In addition, RES energy is necessary because it contributes to energy security since those countries are loosely bounded on imported fossil fuels [17].

Another paper focuses on energy consumption from renewable and non-renewable sources of energy in relation to international trade [18]. This survey examines the correlation between energy production and consumption from both renewable and non-renewable sources and international trade, examining 69 countries for the period between 1980 and 2010. The results contain indicators of a two-way causality between production and trade. These results show that any changes in trade can influence the economic outcome and, accordingly, changes in production can affect trade. In the short run, no link is reported between GDP and green energy consumption. However, there is a long-run two-way relationship between the variables.

Sadorsky [19] develops economic models for studying the consumption of energy from RES in relation to income, especially among emerging economies. The researcher perceives a relationship between income and green energy consumption as a prerequisite for the design of an effective energy policy. The model uses data from 18 emerging economies and focuses on the per capita consumption of energy from RESs and the per capita income. According to the analysis, a rise in GDP leads to an increase in energy consumption from renewables. High income is identified as significant by the model over the long run, suggesting that slight changes to GDP highly impact the consumption of energy from renewable sources. In conclusion, the results show that a slight increase in per capita income is directly causing a significant increase in RES consumption in the case of emerging economies.

By looking at the correlation between renewable energy and GDP in the case of the United States, the consumption is directly related to biomass-made energy [20]. No other relationship exists between real GDP and all other renewable energy sources examined, namely total RES consumption, geothermal energy consumption, hydropower consumption, and biomass energy consumption. The results of this study conclude that the generation of energy from waste is of utmost importance [20].

Fang [21] examines the impact of RES consumption on China's GDP. By using regression techniques, the analysis concludes that a $1 \%$ increase in RES consumption leads to $0.162 \%$ GDP growth, $0.44 \%$ for rural households and $0.368 \%$ for urban households. However, it is suggested that the expansion of the RES share inevitably provides politico-economic hurdles. Obstacles are attributed to the environmental impacts of fossil fuels use, which contain costs for society, such as human health degradation, infrastructure, decline in forests and fisheries, and increased spending associated with tackling climate change [21]. Concerning the economic stance, the researcher states that when all the external economies are considered, some RESs, especially wind power, are proven cheaper than conventional sources. Regarding political barriers, lack of coordination, unsupportive policy encouragement, as well as government grants that are inadequately developed in terms of geographical coverage or sound research contexts of analysis are reported [21].

In another study for the Chinese context, the relationship between RES consumption and economic growth is examined for the period 1977-2011 [22]. The results show a two-way relationship in the long-run between the RES consumption and GDP. This finding suggests that China's growing economy is conducive to the development of the renewable energy sector, offering promising contribution to further economic growth [22].

Shahbaz et al. [11] explore the relationship between RES consumption and GDP in Pakistan. Their analysis uses an econometric log-linear distribution model where the per capita GDP is the independent variable, while the per capita energy consumption, labor force, and gross fixed capital formation are the independent ones. Long-run results show that the model of renewable energy consumption can stimulate economic growth stronger than the opposite model, which shows that economic growth 
motivates the use of RESs. According to the researchers, the government should propose an integrated energy policy towards the exploitation of new RESs. Furthermore, local governments should promote investments in RESs to overcome the national energy crisis [11].

On the contrary, a similar study using regression models for the case of Turkey did not report any impact from RES-produced electricity consumption on GDP [23]. However, the non-renewable electricity consumption variable was statistically significant in the long-run, as a $1 \%$ increase in energy consumption led to a minor increase in GDP. Researchers therefore confirm the country's dependence on conventional energy sources and propose an expanding investment in conventional energy sources, by reducing the contributing share of RESs at the national energy mix [23].

Under this non-European context, another significant interdisciplinary research shows that the existing regulatory framework for the electricity and renewables sectors is an extremely important parameter that especially affects the role of regulatory agencies in Northern Africa and Middle East countries, under the promotion by the EU [24]. In this research, authors stress that in countries where an independent regulator operates, increased regulatory credibility exists in comparison to countries in which such a body does not exist. Besides, in those countries where regulatory framework is limiting administrative expropriation it, consequently, creates a more suitable environment for attracting investments in electricity production using renewables [24].

In another research work, the strategic environmental assessment (SEA) has been introduced as a comprehensive framework for the assessment of policies and plans [25]. The authors denote that suitable energy models, ecological assessment models, and multi-criteria approaches exist with immense potential for interconnection, which could be advanced into powerful SEA tools for integrated policy assessment [25].

In a global context [26], it is reported that since developed economies are confronting a persistent decline in economic growth, it is of utmost importance for the technological spur of renewables to support the energy autonomy of national energy mixes without creating irreversible environmental pollution. Particularly, the use of the Hurlin-Granger causality test shows that there is a unidirectional causality linkage from agricultural production to electricity consumption for non-coastal regions, and furthermore, there is a bidirectional relationship between agricultural electricity consumption and output for numerous coastal regions.

Recently, Sutter [27] organized the main concerns to which Americans are mindful of energy efficiency as accordingly: first, for their cars, appliances, homes, and machinery, and second, as the mandating of the use of renewable fuels in electricity production. The main representative foundation upon renewable energy resources utilization in the US is the Department of Energy (DOE).

In this respect, Cherukupalli [28] reports that though a dynamic progress in all areas of electro-technology is achieved in developed countries, a significant part of the population has low or no access to electricity. The author [28] also stresses that life and economic activity in large areas of the developing world remains unchanged, as access to reliable electricity is an extremely important aspect of enjoyment, benefits, and modern conveniences.

Finally, another study was conducted in the US context by Haerer and Pratson [29] who investigate the employment trends in the US electricity sector for the period 2008-2012. The authors denote that even though electricity production that was generated from coal declined, the percentage of jobs lost were offset two times higher by the increased employment rates from the expansion of RES-operated industries, especially, natural gas, solar, and wind. Furthermore, US sustain a well-developed, life cycle analysis-based energy sector, along with advanced electricity supply chain. On the other hand, the adaptability of the aforementioned outcomes to developing economies-where switching fuel types is a complex policy, or there exists RES-deprivation-shows slow adaptability and ineffective economies-of-scale achievement. 


\subsection{European Countries}

In a recent publication, wind energy (terrestrial and offshore), hydro (small and large), and nuclear energy are the most preferable technologies [30]. The results identify a failure to reach emission reduction targets. To achieve this, it is necessary to increase the share of all zero emission technologies by $1-2 \%$. It is stressed that offshore wind energy is the largest renewable energy technology $(20.28 \%)$. Relevant studies conclude that an efficient, safe, and environmentally friendly energy future in the EU is closely related to RESs [30,31].

Another study investigates the consumption of fossil fuels and RESs, greenhouse gases, and economic growth, using EU countries' data, unveiling a relationship between greenhouse emissions and GDP [32]. Moreover, economic growth cannot affect emissions reduction, since from one point onwards, there is an upsurge in the phenomenon.

A study about developing European countries identifies an overall long-run relationship between energy consumption and GDP, while a short-run two-way relationship is reported for Hungary, Poland, Turkey, and Romania [33]. Consequently, RES consumption plays a determining role in supporting economic growth for numerous countries [17].

Another important aspect is the role of commerce to RES consumption promotion $[16,18]$. In emerging economies, it is reported that a slow increase in the per capita GDP can lead to a significant increase in RES consumption [19].

In the European context, Borkowska and Klimczak [34] argue that like other network industries (telecommunication, gas, rail), electricity was transformed from a monopoly to an imperfectly competitive market. The authors examine the electricity reform in Poland, showing that the reform failed in key aspects, such as industry restructuring, the creation of a transparent wholesale spot energy market, and the foundation of other institutions necessary to create clear rules to achieve reasonably competitive performance results. The lack of a sound regulatory implementation was the cause of the predominance of state ownership in the electricity industry and strong politicization of the industry [34].

In the Greek context, Tellidou and Bakirtzis [35] employ a research study upon the energy market performance to exercise the monopoly power. Test results on a two-node power system with two competing generator-agents demonstrated the negative effects of a monopoly [35].

Furthermore, Philippou et al. [36] first explore the opening of the electricity market in Greece. A decade later, Andrianesis et al. [37] denote that Greece's electricity market can be divided in two zones, due to the generation-consumption system configuration that creates an important transmission barrier from north to south. The authors also used a simplified model of the Greek electricity system that includes only the thermal power plants. An analysis upon the commodities of energy and ancillary services under the marginal pricing approach is presented [37]. A zonal pricing approach for energy provides the right incentive for the installation of new generation near consumption, if the zonal configuration reflected the actual system and operational conditions. Authors extend the zonal approach to include time response-based ancillary services, which were commodities that can be traded in the day-ahead market and are co-optimized with energy. Focusing on the day-ahead scheduling (DAS) market problem, which is formulated as a security-constrained unit-commitment problem, its objective is to co-optimize energy and reserves by considering the generation units' commitment costs. A dual analysis of the problem and calculation of shadow prices offers useful insight into how prices for each commodity are set in the presence of binding resource, transmission, or zonal reserve constraints.

Finally, in a technological applicability of RESs in the European context, Chatzisideris et al. [38] focus on organic photovoltaics (OPV), which are an emerging thin-film PV technology that promises to greatly improve the environmental and economic performances of PV technologies. While generic results are applied to all PV technologies, it is shown that PV systems installed in Greek houses, perform economically better than those in Denmark. Focusing on organic PV systems developed in an industrial-scale cost setting $(1.53 € / \mathrm{Wp})$, it is argued that they deliver significant electricity bill savings 
for residential houses in Greece (38\%) under current conditions, while they may not be sufficiently attractive for residential houses in Denmark (6.5\%) mainly due to the different PV regulatory schemes. It is also noteworthy that investors interested in renewable energy technologies need to pursue scaling up the manufacturing capacity of OPV technologies, as well as assess a large number of countries to identify and prioritize financially attractive settings for PV self-consumption [38].

\section{Data and Methods}

To examine RES' consumption correlation with countries' economic growth, Eurostat's latest dataset (updated in May 2018) concerning 25 European countries for the period between 2007 and 2016 is used [39]. Due to the risk of different measurement methodology that can lead to biased results, other data sources, such as OECD or IEA data, are not inserted into our dataset.

Using IBM Corp's SPSS V.20 software, this study employs a hierarchical cluster analysis by using Ward's method in order to classify the examined countries based on their GDP and RES consumption. Cluster analysis methodology is used in other similar studies as well [2]. Furthermore, to examine the relationship between the variables of our interest, a log-linear specification is applied by using an error-corrected autoregressive distributed lag (ARDL). This is a common methodology proposed in similar studies [11,40]. The regression part of the analysis was carried out by using Stata Corp's STATA V.13 software.

The abovementioned log-linear specification investigates the relationship between variables concerning the dependent variable of gross domestic product (GDP) and the independents of RES and Non-RES energy consumption, gross fixed capital formation (GFCF), and labor force in the long-run. Such models, where GDP is set to be predicted by RES and Non-RES' consumption, GFCF and labor force are used in other studies of the same scientific field as well [4-11,40].

\section{Results and Discussion}

Initially, we focussed on energy consumption of the examined countries for the 10-year period of 2007-2016. Figure 1 shows that there is an ongoing shift from fossil fuels to RESs, which depicts the implementation of the European strategy for gradual independence from fossil fuels.

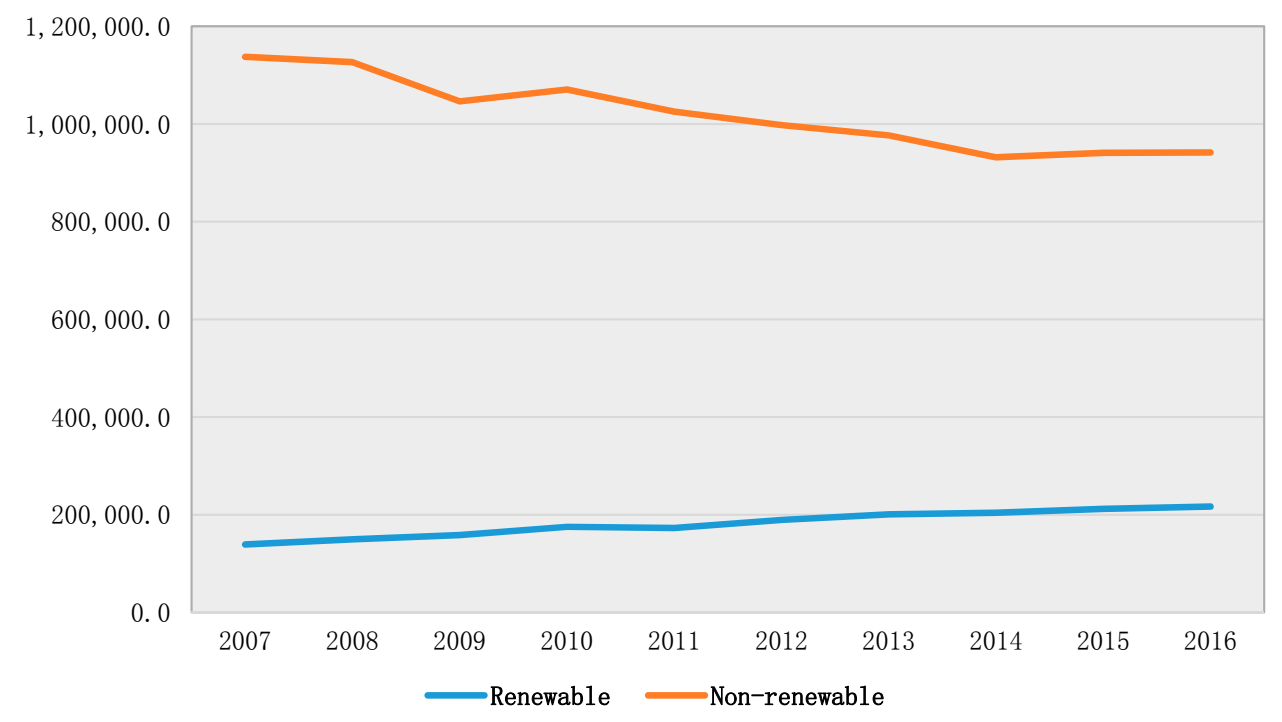

Figure 1. Energy usage in European countries (in thousand tons of oil equivalent (TOE)). Data source: Eurostat [39].

The next step of the analysis was to categorize the countries based on their GDP and energy produced from RESs. According to Equation (1), the countries are clustered by using the Ward's 
method for hierarchical cluster analysis, which considers that the distance between two clusters is how much the sum of squares will increase [41]:

$$
\Delta(,)=\sum_{i \in A \cup B}\left\|\vec{x}_{i}-\vec{m}_{A \cup B}\right\|^{2}-\sum_{i \in A}\left\|\vec{x}_{i}-\vec{m}_{A}\right\|^{2}-\sum_{i \in B}\left\|\vec{x}_{i}-\vec{m}_{B}\right\|^{2}
$$

where $\vec{m}$ denotes the cluster's centers. This method minimizes the variances within clusters as much as possible $[3,41]$. Based on Ward's method dendrogram, two clusters were identified, as shown in Figure 2.

\begin{tabular}{l} 
Romania \\
Bulgaria \\
Lithuania \\
Greece \\
Ukraine \\
Czech Republic \\
Poland \\
Hungary \\
Belarus \\
Slovakia \\
Norway \\
France \\
Switzerland \\
Finland \\
Republic of Ireland \\
Netherlands \\
United Kingdom \\
Belgium \\
Austria \\
Italy \\
Germany \\
Sweden \\
Spain \\
Portugal \\
Denmark \\
\hline
\end{tabular}

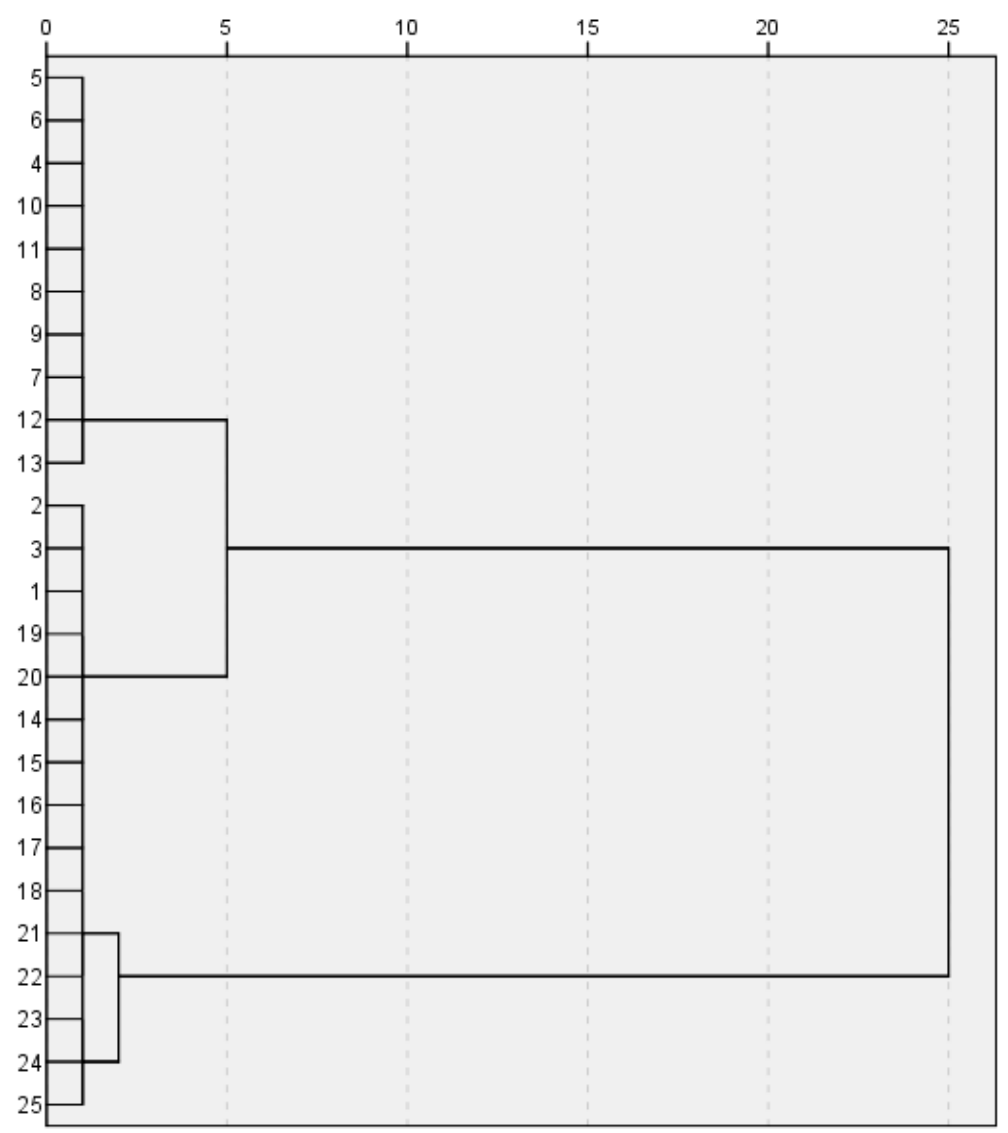

Figure 2. Dendrogram using Ward's method.

As we can see in Table 1, high GDP countries with high consumption of RESs were classified in cluster 1 (60\% of countries); countries with low GDP and low consumption of RESs were classified in cluster 2.

Table 1. Countries clusters according to GDP and RES consumption.

\begin{tabular}{cccc}
\hline \multicolumn{3}{c}{ Cluster Distribution } \\
\hline & Number of Countries & \% of Combined \\
\hline \multirow{4}{*}{ Cluster } & 1 & 10 & $40.0 \%$ \\
& 2 & 15 & $60.0 \%$ \\
& Combined & 25 & $100.0 \%$ \\
\hline
\end{tabular}

As we can note at Table 2, the average GDP for countries belonging in cluster 1 is 34,548 Euros per capita; in the second cluster there is an average of 16,526 Euros. The per capita consumption of renewable energy of the first cluster is 0.254 tons of oil equivalent (TOE), while the second cluster 
consumes 0.049 TOE. It is remarkable that the countries of the first cluster have a considerable deviation while the countries of the second cluster appear to be more concentrated around their mean.

Table 2. Clusters according to GDP per capita (in thousand Euros) and renewable energy consumption per capita (in tons of oil equivalent).

\begin{tabular}{cccccc}
\hline & \multicolumn{2}{c}{$\begin{array}{c}\text { GDP per Capita } \\
\text { (in Thousand Euros) }\end{array}$} & $\begin{array}{c}\text { RES Consumption per Capita } \\
\text { (in TOE) }\end{array}$ \\
\hline & Mean & Std. Deviation & Mean & Std. Deviation \\
\hline \multirow{2}{*}{ Cluster } & 1 & 34.548 & 7.430 & 0.254 & 0.160 \\
& 2 & 16.526 & 5.760 & 0.049 & 0.039 \\
\hline
\end{tabular}

The above results show a potential correlation between RES consumption and economic growth. This obtained correlation between economic growth and RES consumption is depicted in the following scatter diagram, Figure 3, below. More specifically, it is obvious that most of the countries of higher GDP (cluster 1) had higher RES consumption than those of lower GDP (cluster 2).

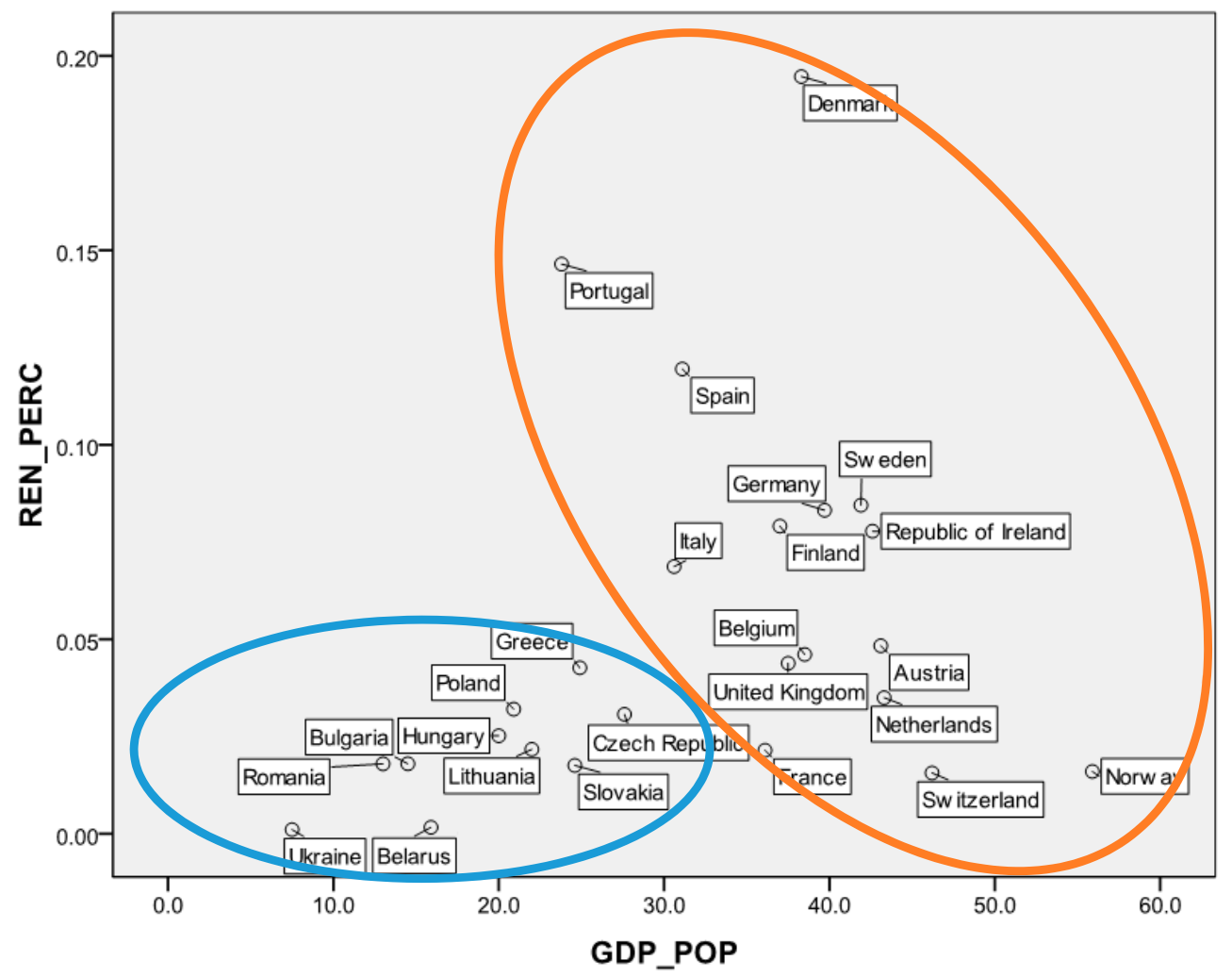

Figure 3. European countries according to RES consumption and GDP. Data source: Eurostat [39].

To attest and further analyze the observed correlation between RES consumption and economic growth in the long-run, we used a production function (Equation (2)), as proposed in other studies [4-11,40]:

$$
G D P=f(G F C F, L F, R E S, N O N R E S)
$$

where:

- GDP denotes the gross domestic product;

- GFCF denotes the gross fixed capital formation; 
- $\quad$ LF denotes the total labor force;

- RES denotes the renewable energy sources consumption; and

- NONRES denotes the non-renewable energy consumption

To examine the possible correlation between the abovementioned variables during the examined period, a log-linear specification was used (Equation (3)). The applied log-linear specification was of the following form:

$$
\ln G D P_{t}=a_{0}+a_{1} \ln G F C F_{t}+a_{2} \ln L F_{t}+a_{3} \ln R E S_{t}+a_{4} \ln N O N R E S_{t}+u_{t}
$$

The above log-linear specification was examined using an autoregressive distributed lag (ARDL) as according to many authors it has more advantages over other techniques [11]. The main ARDL model's equation (Equation (4)) is of the following form [42]:

$$
y_{t}=c_{0}+c_{1} t+\sum_{i=1}^{p} \varphi_{i} y_{t-i+} \sum_{i=0}^{q} \beta_{i}^{\prime} x_{t-i}+u_{t}
$$

The above model was reparametrized as follows (Equation (5)) to be error-corrected [42-44]:

$$
\Delta y_{t}=c_{0}+c_{1} t-\left(1-\sum_{j=1}^{p} \varphi_{i}\right)\left(y_{t-1}-\frac{\sum_{j=0}^{q} \beta_{j}}{a} x_{t-1}\right)+\sum_{i=1}^{p-1} \psi_{y i} \Delta y_{t-i}+\omega^{\prime} \Delta x_{t}+\sum_{i=1}^{q-1} \psi_{x i}^{\prime} \Delta x_{t-i}+u_{t}
$$

Based on the above analysis, the data of Table 3 was obtained. This table summarizes the results for the log-linear specification models. More specifically, it concerns the impact of predictors for the

\begin{tabular}{|c|c|c|c|c|c|}
\hline Model & Variables in Model & Coefficient & Std. Error & F-Statistic & $p$-Value \\
\hline \multirow{9}{*}{$\begin{array}{l}\text { Model for cluster } 1 \text { countries. } \\
\text { Dependent: } \ln _{\text {GDP }}\end{array}$} & Constant & $15,979.230$ & 9517.702 & 6.978 & 0.000 \\
\hline & $\operatorname{lnGFCF} F_{t}$ & 1.760 & 2.514 & 4.929 & 0.006 \\
\hline & $\ln L F_{t}$ & 0.722 & 0.444 & 6.413 & 0.000 \\
\hline & $\operatorname{lnRES} S_{t}$ & 0.603 & 0.231 & 20.070 & 0.001 \\
\hline & $\operatorname{lnNONRES} \mathrm{t}_{\mathrm{t}}$ & 0.310 & 0.504 & 7.245 & 0.000 \\
\hline & Diagnostic Tests & Test Values & $p$-Value & & \\
\hline & F-Statistic & 22.380 & 0.000 & & \\
\hline & Jarque-Bera & 0.194 & 0.812 & & \\
\hline & Adjusted R-squared & 0.680 & & & \\
\hline \multirow{9}{*}{$\begin{array}{l}\text { Model for cluster } 2 \text { countries. } \\
\text { Dependent: } \ln _{\mathrm{GDP}} \mathrm{t}\end{array}$} & Constant & 8848.629 & 3367.971 & 6.210 & 0.000 \\
\hline & $\operatorname{lnGFCF} F_{t}$ & 2.932 & 0.258 & 9.070 & 0.002 \\
\hline & $\operatorname{lnLF} F_{t}$ & 0.152 & 1.074 & 7.032 & 0.008 \\
\hline & $\ln R E S_{t}$ & 0.477 & 0.497 & 16.0766 & 0.000 \\
\hline & $\operatorname{lnNONRES} S_{\mathrm{t}}$ & 0.718 & 0.586 & 6.649 & 0.000 \\
\hline & Diagnostic Tests & Test Values & $p$-Value & & \\
\hline & F-Statistic & 20.070 & 0.000 & & \\
\hline & Jarque-Bera & 0.208 & 0.753 & & \\
\hline & Adjusted R-squared & 0.738 & & & \\
\hline
\end{tabular}
examined countries' economic growth as it is measured based on their GDP.

Table 3. Variables and coefficients of the error-corrected log-linear specification models.

The first critical step was to find evidence that there was a correlation between GDP and its predictors for the examined period. This evidence was deduced from the F-Statistic values as shown in Table 3. Specifically, the F-Statistic values were greater than their upper critical bounds as they were proposed for the analysis of level relationship tests [44] and cointegration tests for less than 30 observations $[42,45]$. Thus, we can confirm that there was a statistically significant correlation between GDP and its predictors in the long-run concerning the countries of both the examined clusters. 
Furthermore, in all the examined cases, the p-values were less than $1 \%$, which means that there was a positive correlation between the examined GDPs and their predictors at $1 \%$ level of significance.

For the countries belonging to cluster 1, RES's coefficient was equal to 0.603; thus, if RES consumption increases by $1 \%$, and the other predictors of economic growth remain constant (ceteris paribus), the countries' GDP will increase by $0.603 \%$. Similarly, as far as the countries of cluster 2 were concerned, when RES consumption increases by $1 \%$, ceteris paribus, the countries' GDP will increase by $0.477 \%$.

Based on the adjusted R-squared values, the independent variables explained $68 \%$ of the first cluster countries' economic growth; as far as the second cluster's countries are concerned, the independent variables explained $74 \%$ of their economic growth. Moreover, the diagnostic tests' results show that both the proposed models had a reasonable good fit; there was no serial correlation, while skewness and kurtosis matching normal distribution and homoscedasticity were shown.

Consequently, RES consumption seemed to be correlated with the economic growth of both clusters' countries in the long-run. However, this correlation was higher with the economic growth of countries with higher GDP, while countries with lower economic growth were more dependent on Non-RESs.

\section{Conclusions}

The aim of this study was to investigate the relationship between RES consumption and countries' economic growth. To examine this relationship, data concerning 25 European countries' GDP, RES consumption, Non-RES consumption, GFCF, and labor force were statistically analyzed using the Ward's method for hierarchical cluster analysis. This method revealed the existence of two countries' clusters; a cluster of high GDP and high RES consumption countries and another cluster of low GDP and low RES consumption countries.

To sharpen the above results and further examine the correlation between RES consumption and a country's GDP, a log-linear specification by applying an error-corrected autoregressive distributed lag (ARDL) was employed. The results of this analysis for the countries of the two clusters suggest that there was a statistically significant correlation between GDP and its predictors in the long-run. More specifically, as far as energy consumption is concerned, the applied models indicated that RES's correlation was higher with high GDP countries; on the other hand, countries with lower GDP rely more on Non-RESs.

The results also discovered a prominent level of heterogeneity concerning the deployment of RESs in the examined countries' energy policy. For the case of low RES usage between several high GDP countries, the results are likely to indicate a low level of know-how on their effective usage. Furthermore, this could be the result of the lack of financial resources for a higher level of RES inclusion to these countries' energy mix. A two-sided interrelation between RES consumption and GDP growth is possible to exist as well [16]. This interrelation is the subject of further analysis.

The above findings show that policy-makers of both high and low GDP countries should take all the needed measures to increase RES contribution to the energy mix. Such measures involve the creation of a friendly environment for large-scale investments in RESs [46] and the provision of other incentives such as financial facilities to citizens [47-50]. Financial support is necessary since the richest countries can afford to use RESs. Furthermore, the creation of a common EU-wide energy production balance is critical as even countries that cannot produce a type of renewable energy due to their restricted natural resources (e.g., northern countries do not have the adequate sunlight to produce solar energy) can use RESs by relying to imports from other countries. Moreover, the development of know-how and the removal of economic and political barriers are some of the important steps towards the further development and deployment of RESs [4].

Based on the subject of the present study, there are several avenues for future research. First, it may be useful to apply various statistical techniques such as Augmented Dickey-Fuller (ADF) or Kwiatkowski-Phillips-Schmidt-Shin (KPSS) tests to better understand the relationship between 
renewable energy consumption and economic growth. Moreover, since carbon emissions reduction is a core feature of EU's environmental strategy, it would be useful to add it as an additional parameter to the statistical analysis [2]. Lastly, a comparative analysis between the EU and other countries could highlight the potential differences in the use of RESs and, at the same time, their global contribution to economic development.

Author Contributions: S.N., M.S., and M.C. gathered the data and carried out the implementation, and performed the calculations and the computer programming. G.K., G.A., S.G., and A.B. gathered and implemented all the theoretical background of the paper, and having the input from the experimental development, they reviewed and discussed the results of the study as well. A.K. performed the overall grammar check based on the narrative and its smoothing throughout the text content.

Funding: This research received no external funding.

Conflicts of Interest: The authors declare no conflict of interest.

\section{References}

1. Rodríguez-Monroy, C.; Mármol-Acitores, G.; Nilsson-Cifuentes, G. Electricity generation in Chile using non-conventional renewable energy sources-A focus on biomass. Renew. Sustain. Energy Rev. 2018, 81, 937-945. [CrossRef]

2. Ntanos, S.; Ziatas, T.; Merkouri, A. Renewable energy consumption, carbon dioxide emissions and economic growth: Evidence from Europe and Greece. In Proceedings of the e-RA 10 International Scientific Conference, Piraeus, Greece, 23-25 September 2015; pp. 46-56.

3. Papageorgiou, A.; Skordoulis, M.; Trichias, C.; Georgakellos, D.; Koniordos, M. Emissions trading scheme: Evidence from the European Union countries. In Communications in Computer and Information Science; Kravets, A., Shcherbakov, M., Kultsova, M., Shabalina, O., Eds.; Springer International Publishing: Cham, Switzerland, 2015; pp. 222-233.

4. Svenfelt, Å.; Engström, R.; Svane, Ö. Decreasing energy use in buildings by $50 \%$ by 2050 -A backcasting study using stakeholder groups. Technol. Forecast. Soc. Chang. 2011, 78, 785-796. [CrossRef]

5. Alper, A.; Oguz, O. The role of renewable energy consumption in economic growth: Evidence from asymmetric causality. Renew. Sustain. Energy Rev. 2016, 60, 953-959. [CrossRef]

6. Apergis, N.; Danuletiu, D.C. Renewable energy and economic growth: Evidence from the sign of panel long-run causality. Int. J. Energy Econ. Policy 2014, 4, 578-587.

7. Destek, M.A.; Aslan, A. Renewable and non-renewable energy consumption and economic growth in emerging economies: Evidence from bootstrap panel causality. Renew. Energy 2017, 111, 757-763. [CrossRef]

8. Pao, H.T.; Fu, H.C. Renewable energy, non-renewable energy and economic growth in Brazil. Renew. Sustain. Energy Rev. 2013, 25, 381-392. [CrossRef]

9. Koçak, E.; Şarkgüneşi, A. The renewable energy and economic growth nexus in Black Sea and Balkan countries. Energy Policy 2017, 100, 51-57. [CrossRef]

10. Sasana, H.; Ghozali, I. The impact of fossil and renewable energy consumption on the economic growth in Brazil, Russia, India, China and South Africa. Int. J. Energy Econ. Policy 2017, 7, 194-200.

11. Shahbaz, M.; Loganathan, N.; Zeshan, M.; Zaman, K. Does renewable energy consumption add in economic growth? An application of auto-regressive distributed lag model in Pakistan. Renew. Sustain. Energy Rev. 2015, 44, 576-585. [CrossRef]

12. Salim, R.A.; Hassan, K.; Shafiei, S. Renewable and non-renewable energy consumption and economic activities: Further evidence from OECD countries. Energy Econ. 2014, 44, 350-360. [CrossRef]

13. Apergis, N.; Payne, J.E. Renewable and non-renewable energy consumption-growth nexus: Evidence from a panel error correction model. Energy Econ. 2012, 34, 733-738. [CrossRef]

14. Bhattacharya, M.; Paramati, S.R.; Ozturk, I.; Bhattacharya, S. The effect of renewable energy consumption on economic growth: Evidence from top 38 countries. Appl. Energy 2016, 162, 733-741. [CrossRef]

15. Inglesi-Lotz, R. The impact of renewable energy consumption to economic growth: A panel data application. Energy Econ. 2015, 53, 58-63. [CrossRef]

16. Omri, A.; Nguyen, D.K. On the determinants of renewable energy consumption: International evidence. Energy 2014, 72, 554-560. [CrossRef] 
17. Al-Mulali, U.; Fereidouni, H.G.; Lee, J.Y.; Sab, C.N. Examining the bi-directional long run relationship between renewable energy consumption and GDP growth. Renew. Sustain. Energy Rev. 2013, 22, $209-222$. [CrossRef]

18. Jebli, M.B.; Youssef, S.B. Output, renewable and non-renewable energy consumption and international trade: Evidence from a panel of 69 countries. Renew. Energy 2015, 83, 799-808. [CrossRef]

19. Sadorsky, P. Renewable energy consumption and income in emerging economies. Energy Policy 2009, 37, 4021-4028. [CrossRef]

20. Yildirim, E.; Saraç, Ş.; Aslan, A. Energy consumption and economic growth in the USA: Evidence from renewable energy. Renew. Sustain. Energy Rev. 2012, 16, 6770-6774. [CrossRef]

21. Fang, Y. Economic welfare impacts from renewable energy consumption: The China experience. Renew. Sustain. Energy Rev. 2011, 15, 5120-5128. [CrossRef]

22. Lin, B.; Moubarak, M. Renewable energy consumption-Economic growth nexus for China. Renew. Sustain. Energy Rev. 2014, 40, 111-117. [CrossRef]

23. Dogan, E. The relationship between economic growth and electricity consumption from renewable and non-renewable sources: A study of Turkey. Renew. Sustain. Energy Rev. 2015, 52, 534-546. [CrossRef]

24. Cambini, C.; Franzi, D. Assessing the EU Pressure for Rules Change: The Perceptions of Southern Mediterranean Energy Regulators. Mediterr. Politics 2014, 19, 59-81. [CrossRef]

25. Pang, X.; Mörtberg, U.; Brown, N. Energy models from a strategic environmental assessment perspective in an EU context-What is missing concerning renewables? Renew. Sustain. Energy Rev. 2014, 33, 353-362. [CrossRef]

26. Dogan, E.; Sebri, M.; Turkekul, B. Exploring the relationship between agricultural electricity consumption and output: New evidence from Turkish regional data. Energy Policy 2016, 95, 370-377. [CrossRef]

27. Sutter, D. Propagandistic Research and the U.S. Department of Energy: Energy Efficiency in Ordinary Life and Renewables in Electricity Production. Econ. J. Watch 2017, 14, 103-120.

28. Cherukupalli, N. Renewables Can Help Transform Lives in Rural Areas. Proc. IEEE 2015, 103, 862-867. [CrossRef]

29. Haerer, D.; Pratson, L. Employment trends in the U.S. Electricity Sector, 2008-2012. Energy Policy 2015, 82, 85-98. [CrossRef]

30. DeLlano-Paz, F.; Calvo-Silvosa, A.; Antelo, S.I.; Soares, I. The European low-carbon mix for 2030: The role of renewable energy sources in an environmentally and socially efficient approach. Renew. Sustain. Energy Rev. 2015, 48, 49-61. [CrossRef]

31. Knopf, B.; Nahmmacher, P.; Schmid, E. The European renewable energy target for 2030-An impact assessment of the electricity sector. Energy Policy 2015, 85, 50-60. [CrossRef]

32. Bolük, G.; Mert, M. Fossil and renewable energy consumption, GHGs (greenhouse gases) and economic growth: Evidence from a panel of EU (European Union) countries. Energy 2014, 74, 439-446. [CrossRef]

33. Caraiani, C.; Lungu, C.; Dascălu, C. Energy consumption and GDP causality: A three-step analysis for emerging European countries. Renew. Sustain. Energy Rev. 2015, 44, 198-210. [CrossRef]

34. Borkowska, B.; Klimczak, M. From a monopoly towards an imperfectly competitive electricity market in Poland. Transform. Bus. Econ. 2011, 10, 463-474.

35. Tellidou, A.C.; Bakirtzis, A.G. Agent-based analysis of monopoly power in electricity markets. In Proceedings of the International Conference on Intelligent Systems Applications to Power Systems, Kaohsiung, Taiwan, 5-8 November 2007.

36. Philippou, M.; Tassoulis, A.; Katsigiannakis, G. The liberalization process of the electricity market in Greece: The design of the transmission system operator's IT infrastructure. In Proceedings of the International Conference on Electric Power Engineering, PowerTech, Budapest, Hungary, 29 August-2 September 1999; p. 15.

37. Andrianesis, P.; Biskas, P.; Liberopoulos, G. An overview of Greece's wholesale electricity market with emphasis on ancillary services. Electr. Power Syst. Res. 2011, 81, 1631-1642. [CrossRef]

38. Chatzisideris, M.D.; Laurent, A.; Christoforidis, G.C.; Krebs, F.C. Cost-competitiveness of organic photovoltaics for electricity self-consumption at residential buildings: A comparative study of Denmark and Greece under real market conditions. Appl. Energy 2017, 208, 471-479. [CrossRef] 
39. Eurostat. Supply, Transformation and Consumption of Renewable Energies-Annual Data Supply, Transformation and Consumption of Renewable Energies-Annual Data. Available online: http://ec. europa.eu/eurostat/data/database (accessed on 1 June 2018).

40. Taeyoung, J.; Jinsoo, K. Coal Consumption and Economic Growth: Panel Cointegration and Causality Evidence from OECD and Non-OECD Countries. Sustainability 2018, 10, 660. [CrossRef]

41. Punj, G.; Stewart, D.W. Cluster analysis in marketing research: Review and suggestions for application. J. Mark. Res. 1983, 20, 134-148. [CrossRef]

42. Kripfganz, S.; Schneider, D.C. ARDL: Stata module to estimate autoregressive distributed lag models. In Proceedings of the Stata Conference, Chicago, IL, USA, 28-29 July 2016.

43. Goh, S.K.; Wong, K.N. Could inward FDI offset the substitution effect of outward FDI on domestic investment? Evidence from Malaysia. Prague Econ. Pap. 2014, 23, 413-425.

44. Pesaran, M.H.; Shin, Y.; Smith, R.J. Bounds testing approaches to the analysis of level relationships. J. Appl. Econ. 2001, 16, 289-326. [CrossRef]

45. Narayan, P.K. The saving and investment nexus for China: Evidence from cointegration tests. Appl. Econ. 2005, 37, 1979-1990. [CrossRef]

46. Azam, M.; Khan, A.Q.; Zafeiriou, E.; Arabatzis, G. Socio-economic determinants of energy consumption: An empirical survey for Greece. Renew. Sustain. Energy Rev. 2016, 57, 1556-1567. [CrossRef]

47. Ntanos, S.; Kyriakopoulos, G.; Chalikias, M.; Arabatzis, G.; Skordoulis, M.; Galatsidas, S.; Drosos, D. A Social Assessment of Renewable Energy Sources Usage and Contribution to Life Quality: The Case of an Attica Urban Area in Greece. Sustainability 2018, 10, 1414. [CrossRef]

48. Ntanos, S.; Kyriakopoulos, G.; Chalikias, M.; Arabatzis, G.; Skordoulis, M. Public Perceptions and Willingness to Pay for Renewable Energy: A Case Study from Greece. Sustainability 2018, 10, 687. [CrossRef]

49. Menanteau, P.; Finon, D.; Lamy, M.L. Prices versus quantities: Choosing policies for promoting the development of renewable energy. Energy Policy 2003, 31, 799-812. [CrossRef]

50. Garcia, A.; Alzate, J.M.; Barrera, J. Regulatory design and incentives for renewable energy. J. Regul. Econ. 2012, 41, 315-336. [CrossRef] 